\title{
Clinicopathological and Prognostic Characteristics of Hepatoid Adenocarcinoma of the Stomach
}

\author{
Chenxu Liu \\ Zhengzhou University First Affiliated Hospital https://orcid.org/0000-0002-0370-0294 \\ Yanru Qin ( $\square$ liucx0711@163.com) \\ First Affiliated Hospital of Zhengzhou University https://orcid.org/0000-0001-7576-5129 \\ Zhiwei Chang \\ First Affiliated Hospital of Zhengzhou University \\ Wenjia Wang \\ First Affiliated Hospital of Zhengzhou University \\ Chen Liu \\ First Affiliated Hospital of Zhengzhou University \\ Lin Dong \\ First Affiliated Hospital of Zhengzhou University
}

\section{Research}

Keywords: Stomach, carcinoma, hepatoid adenocarcinoma, clinicopathological features, prognosis

Posted Date: August 12th, 2020

DOI: https://doi.org/10.21203/rs.3.rs-56055/v1

License: (c) (i) This work is licensed under a Creative Commons Attribution 4.0 International License. Read Full License 


\section{Abstract}

Objectives The aim of this study is to analyze the clinical and pathological features of HAS and investigate the factors affecting prognosis.

Methods From January 2014 to May 2020, 31 patients were diagnosed as HAS in in the First Affiliated Hospital of Zhengzhou University. The clinicopathologic features and the relevant prognosis of these patients were analyzed.

Results Of the 31 patients, 23 were male, with a median age of 62 years. And among the 31 patients, 22 patients underwent a radical gastrectomy and a D2 lymph node dissection. During the follow up period, 18 patients died of the disease. The median OS (mOS) was 28 months. The 1 -year survival rate was 55\%, the 3-year survival rate was 47\%, and the 5-year survival rate was $34 \%$. An elevated CA125 level, distant metastasis, and radical surgery were associated with the prognosis of HAS, and distant metastasis is an independent prognostic risk factor for survival.

Conclusion HAS had a poor prognosis because of its frequent vascular involvement, and lymph node and liver metastasis. Aggressive multimodal treatment comprising radical gastrectomy and adjuvant chemotherapy is warranted.

This article describes the Clinicopathological of Hepatoid Adenocarcinoma of the Stomach and through survival analysis, the factors affecting the patient's prognosis were studied.

\section{Introduction}

Hepatoid adenocarcinoma (HAC) is a particular type of extrahepatic adenocarcinoma with morphological characteristics similar to hepatocellular carcinoma (HCC) [1].In 1985, Ishikura et al. reported a case of AFP-producing primary gastric adenocarcinoma and first described HAC as a type of tumor that produces large amounts of AFP and has morphological and immunohistochemical characteristics of liver differentiation[2].However, in 1997, he reported a case of primary gastric cancer with histological characteristics similar to hepatocellular carcinoma and negative AFP expanding the scope of HAC to have liver differentiation characteristics regardless of whether AFP is positive [3].Nagai et al. also proposed that HAC should be defined based on histological features similar to hepatocellular carcinoma, regardless of whether the tumor produces AFP[4].The stomach is the most common site of HAC[5]. In addition, HAC can also be found in the gallbladder, uterus, lung, bladder, esophagus, colon, and ovary $[1,6]$.The incidence of hepatoid adenocarcinoma of stomach (HAS) accounts for only $0.17-1 \%$ of all gastric cancers [7-10]. The clinical symptoms are not specific compared with the common gastric cancer (CGC), but the prognosis of HAS is worse than CGC because of its frequent vascular involvement, and lymph node and liver metastasis[5, 11].In this retrospective study, we analyzed the clinical and pathological features of 31 cases of HAS and described the factors affecting prognosis.

\section{Materials And Methods}

\section{Patients and pathological staging criteria}

Between January 2014 and May 2020囚a total of 6,078 cases of gastric cancer were treated at our center,of which 31 (0.51\%) were HAS.The enrolled 31 patients were all diagnosed as HAS by our pathology department and the pathological diagnosis information is complete.All tumours were staged according to the American Joint Committee on Cancer (AJCC) TNM Staging Classification for Carcinoma of the Stomach, 8th edition.This study was approved by the Ethics Committee of the First Affiliated Hospital of Zhengzhou University.

\section{Survival analysis and statistical analysis}

The overall survival (OS) time was calculated from the date of diagnosis to the last day of follow-up or the date of death. Follow-up visits were conducted using outpatient visits and telephone calls. All patients were regularly followed up from the date of first hospitalization at our hospital. The final follow-up date was June 2020 ,and no patients were lost to follow-up.

Statistical analysis was performed using IBM SPSS 25.0 software. The survival rate was calculated using the Kaplan-Meier method. Univariate and multivariate survival analysis used the Cox risk proportional regression model, a $\mathrm{P}$ value of $<0.10$ of univariate analysis as the multifactor analysis inclusion standard, and a $\mathrm{P}$ value of $<0.05$ was considered significant.

\section{Results}

\section{Clinical characteristics of HAS patients}

The median age of the patients was 62 years (range, $48-73$ years), males accounted for $74.2 \%$ (23 patients) and females $25.8 \%$ (8 patients).Patients showed differential clinical manifestations at initial diagnosis, there were 11 patients(35.5\%) with upper abdominal pain, 7 patients (22.6\%) with black stools, 5 patients (16.1\%) with upper abdominal discomfort, 3 patients (9.6\%) with abdominal distension, and 2 patients (6.5\%) with nausea and vomiting, 2 patients (6.5\%) with liver occupies were found due to physical examination, and 1 patients (3.2\%) 
with anorexia.Among 5 patients with a history of cancer, 3 patients had a family history of gastric cancer, and 2 patients had a family history of esophageal cancer.A total of 27 patients were tested for serum AFP level at initial diagnosis, and serum AFP levels were normal in 5 patients(18.5\%), and elevated in 22 patients(81.5\%). Among 22 patients whose serum AFP levels were elevated, 7 patients had serum AFP levels above the upper limit of the instrument. The clinical characteristics of patients are shown in Table 1.

\section{Clinicopathological findings}

In this group of patients, 20 (64.5\%) had tumors located in the upper third of the stomach, 1 (3.2\%) had tumors in the middle third, 9 (29.1\%) had tumors in the lower third, and 1 (3.2\%) had tumors occupying the whole stomach. All 31 patients presented with advanced gastric cancer, according to the Borrmann gross type classification, Borrmann type I, II,III and IV were found in 5 (16.1\%), 2 (6.5\%) ,17(54.8\%区and 1 (3.2\%) patients. In addition, the Borrmann type of 6 patients were unknown. Of the 31 tumors, 20 (64.5\%) were pathologically confirmed as poorly differentiated, $9(29.0 \%)$ were moderately to poorly differentiated and $2(6.5 \%)$ were moderately differentiated, and there was no welldifferentiated tumors. The pathological findings are shown in Table 1.

Among the 31 patients, TNM classification revealed the presence of 1 patient $\varangle 3.2 \%$ ) with stage I, 6 patients (19.4\%) with stage II, 15 patients (48.4\%) with stage III, and 9 patients (29.0\%) with stage IV cancer. At the first visit, 25 patients (80.6\%) had regional lymph node metastasis and 9 (29.0\%) had distant metastasis. Of the 9 cases, liver metastasis was found in 8 cases, retroperitoneal lymph node metastasis was found in 4 cases, and left supraclavicular lymph node metastasis was found in 1 case.

Immunohistochemical staining of AFP was performed in tumor specimen for each patient, of these, 24 patients (77.4\%) showed positive or focal positive. And among the 24 patients, 1 patient with normal serum AFP level. Immunohistochemical staining of CEA were used in 17 patients, 11 (64.7\%) were positive or focal positive. And immunohistochemical staining of Glypican-3 was performed in 18 patients, 14 (77.8\%) were positive or focal positive. For Ki67, they presented an expression positive at 100\%, and among them, 22(71.0\%) had positive area more than $50 \%$.Immunohistochemical findings are shown in Table 2.

\section{Treatment}

Among the 31 patients, 22 patients underwent a radical gastrectomy and a D2 lymph node dissection, 1 patient underwent palliative surgery, and 8 patients only received palliative chemotherapy. In 22 patients who who underwent a radical operation, 16 patients had received postoperative adjuvant chemotherapy, the chemotherapy regimen is mostly 5-fluorouracil (5fu) plus platinum.

\section{Outcomes of HAS patients}

The median follow-up time for the 31 patients was 14 months (range $0.5-63$ months).During the follow up period, 18 patients died of the disease. The median OS was 28 months. The 1 -year survival rate was $55 \%$, the 3 -year survival rate was $47 \%$, and the 5 -year survival rate was $34 \%$ (Fig. 1 ). Univariate Cox regression analysis revealed that an elevated CA125 level, distant metastasis, and radical surgery were associated with prognosis $(P<0.05)$.A multivariate analysis further revealed that distant metastasis remained an independent prognostic risk factor for survival $(P=0.038$; $\mathrm{HR}=27.016,95 \% \mathrm{Cl}: 1.205 \sim 605.664)$. The survival analysis results are presented in Table 3.

\section{Discussion}

$\mathrm{HAC}$ is a rare special type of extrahepatic adenocarcinoma, the stomach is the most common site of HAC. The mechanism of HAS is not fully understood. Ishikura et al. believed that HAS originated from endoderm stem cells, which can differentiate into hepatocyte cell lines and/or intestinal cell lines; HAS can also be caused by the transdifferentiation of cells from adenoid to hepatoid[12].Research by Akiyama et al. also showed that hepatoid adenocarcinoma has the same origin as coexisting tubular adenocarcinoma[11].Gastric cancer is closely related to liver cancer. During the embryonic development, the stomach and liver are both developed from the foregut. Therefore, some primary gastric cancers have a differentiation disorder, which eventually leads to their differentiation into hepatocytes and the formation of hepatoid adenocarcinoma [5]. Histopathological features are the gold standard for the diagnosis of HAS. As long as hepatocellular differentiation areas appear in the primary focus of gastric cancer, regardless of whether serum AFP is elevated or immunohistochemical staining is positive for AFP, it can be diagnosed as HAS $[3,5]$. The typical histology of HAS is usually the coexistence of adenocarcinoma area and hepatocellular differentiation area, the two can migrate between each other, and a few are all hepatocellular differentiation areas. The adenocarcinoma area is often located in the gastric mucosa, showing tubular and/or papillary structures with different degrees of differentiation. The tumor cell nuclei are deeply stained, and some tumor cells have transparent cytoplasm and nuclear shift. The hepatocellular differentiation area is often located in other layers of the stomach wall, usually showing morphological similarity to HCC histologically, and polyhedral tumor cells with large central nuclei, prominent nucleoli, and abundant eosinophilic cytoplasm were found in hematoxylin-eosin (HE) staining. Blood sinuses are quite abundant in hepatocellular differentiation area, the tumor cells are arranged in a string, and bile-like substances are visible around some cancer cells (Fig. 2) [1, 2, 4].

HAS has a lower incidence rate, previous studies have shown that it accounts for only $0.17-1 \%$ of all gastric cancers. The difference in proportion is not only related to race and region, but also closely related to the level of diagnosis and treatment. In our study, HAS accounted for $0.51 \%$ of all

Page 3/13 
gastric cancers during the same period, which was consistent with previous studies. Compared with CGC, the clinical manifestations of HAS are not specific[13]. Our analysis shows that the clinical manifestations of HAS include upper abdominal pain, upper abdominal discomfort, meconium, nausea, and anorexia. Wang et al. found that HAS is more common in the elderly, with a higher proportion of males and a higher frequency of intestinal type and liver metastases [14]. Qu et al. studied 95 HAS patients from China, and the results showed that HAS mainly occurs in the elderly, males are more common than females, mainly in the gastric antrum, usually ulcerative, and the degree of differentiation is mostly poorly differentiated[15]. Lin et al. reported that the most common type in HAS is Borrmann type III, and the presence of recent bleeding ulcers can often be seen. In the present study, most of the patients were elderly men with a median age of 62 years. 54.8\% (17/31) were Borrmann III type, 64.5\% (20/31) were poorly differentiated type, consistent with previous studies, but the tumor sites were more common in the upper third of the stomach (20/31). And 22.6\% (7/31) of patients presented with black stool as the initial symptom, which is consistent with the recent bleeding ulcers often seen in tumor lesions in previous studies [10].

Elevated serum AFP levels are an important feature of HAS, but not all HAS patients have elevated serum AFP levels. Su et al. reported an elevated serum AFP level in $84.8 \%$ of patients with HAS, ranging from 1.0 to $475,000 \mathrm{ng} / \mathrm{mL}$ [1]. Another study reported that about $80.6 \%$ of patients with HAS had elevated serum AFP levels [16]. Of the 31 patients in this study, 27 had serum AFP levels detected at the time of diagnosis, and $81.5 \%$ (22/27) patients had elevated serum AFP levels, of which $26.0 \%$ (7/27) patients had higher serum AFP levels than the instrument measurable upper limit. AFP is a glycoprotein produced and secreted by the fetal liver, yolk sac, and gastrointestinal tract, and serum AFP levels drop rapidly after birth. The increase in AFP levels is mainly related to the occurrence of hepatocellular carcinoma (HCC). In addition, many other tumors, such as nonseminoblastic germ cell tumors and endodermal sinus tumors, can also cause AFP levels to increase. Serum AFP level has the significance of disease monitoring, the level generally begin to decrease 1 to 2 weeks after tumor resection, return to normal 2 months after surgery, and increase again when distant metastasis or recurrence occur [17]. Ishikura et al. believe that AFP has an immunosuppressive effect, and its production will affect the prognosis of HAS [12]. Wang et al. believe that preoperative serum AFP levels $\geq 500 \mathrm{ng} / \mathrm{ml}$ are related to OS (P = 0.007) and DFS ( $\mathrm{P}=0.05)$, and preoperative serum AFP level is a sensitive prognostic biomarker for DFS and OS[14]. For patients with HAS, elevated serum AFP level is an important feature, which is great helpful to confirm the diagnosis. It is recommended as a routine test item for patients with gastric cancer to reduce the missed diagnosis rate of HAS.

Immunohistochemical detection is also of great significance for the diagnosis of HAS, but there is no very clear marker. AFP is often diffusely positive in the hepatocellular differentiation area, while it is weakly positive or focally positive in the adenocarcinoma area [2]. The adenocarcinoma area is composed of well-differentiated intestinal epithelial cells and usually contains CEA [5]. The positive rate of Glypican-3 in HAS is higher than that of CGC, and it can be used for the diagnosis of HAS [1]. SALL4 is not expressed in adult normal gastric tissues and HCC, but is partially expressed in normal gastric cancer. In addition, it is diffusely expressed in HAS [18]. Akiyama et al. found that the hepatocellular differentiation area contains AFP positive cells [11]. Kumashiro et al. found that $83 \%$ of patients showed AFP expression [19]. Osada et al. reported that the positive rate of AFP staining in HAS patients was $80 \%$, and the positive rate of Glypican 3 staining was $56 \%$ [20]. Another study reported that AFP staining was found to be positive in $91.6 \%$ of patients, and CEA staining was found to be positive in $78.7 \%$ of patients [1]. In our study, 77.4\% (24/31) patients were positive for AFP staining, 64.7\% (11/17) patients were positive for CEA staining, and 77.8\% (14/18) patients were positive for Glypican-3 staining. We also found that Ki67 positive rate was $100 \%$, of which $71.0 \%$ (22/31) positive area was $>50 \%$. Previous studies also reported that the expression of $\mathrm{Ki}-67$ in the tumor cell nucleus was moderately increased [21]. These results indicate that HAS has a high malignant potential, such as high proliferative activity, weak apoptosis and abundant neovascularization [22], which may be the reason for its poor prognosis.

Compared with CGC, HAS is more common in lymph node metastasis, liver metastasis, and extensive vascular invasion, with a worse prognosis. Lin et al. found that $90 \%$ of patients had lymph node metastasis and/or distant metastasis at the time of diagnosis [10]. Another study found that the total incidence of liver metastases in the HAS group was $75.6 \%$, while the total incidence of liver metastases in the CGC group was $11.5 \%$ ( $<$ 0.01) [13]. Osada et al. found that the incidence of vascular infiltration $(P=0.005)$ and distant metastases $(P=0.0458)$ was higher in hepatoid adenocarcinoma compared with non-hepatoid adenocarcinoma[20]. In the present study, $80.6 \%$ (25/31) of patients had regional lymph node metastasis at first visit, and 29.0\% (9/31) of patients had distant metastasis at first visit. 25.8\% (8/31) of the patients had liver metastasis at the time of first diagnosis, and 4 patients had liver metastasis during follow-up. That is, the incidence of liver metastasis was 38.7\% (12/31), including $25.8 \%$ (8/31) simultaneous liver metastasis and $12.9 \%$ (4/31) metachronous liver metastasis. 66.7\% (14/21) patients had vascular tumor thrombus, and $68.8 \%(11 / 16)$ patients had nerve invasion. This aggressive biological behavior of HAS leads to a poor prognosis. According to Liu et al., the one-year, three-year and five-year survival rates of HAS are $30 \%, 13 \%$ and $9 \%$, respectively, while the CGC group is $95 \%$, $57 \%$ and $38 \%(P<0.01)$ [13]. Qu et al. reported that the 3-year survival rate of HAS was 7.4\%, and the median OS was 10 months. Compared with patients with metastasis, the survival time of patients without metastasis was longer $(P=0.001)$, and the survival of patients receiving surgical treatment longer than patients treated with non-surgical methods $(P=0.046)$. Survival analysis showed that survival time was associated with metastasis $(P=0.002)$ and liver metastasis $(P=0.036)[15]$. Another study found that the interval between gastrectomy and liver metastases in patients with HAS is shorter than CGC, resulting in a poorer prognosis[8]. Baek et al. reported that the median OS of patients with stage I-III and stage IV HAS was 28.0 and 8.2 months, respectively[6]. Zeng et al. found that vascular infiltration, pTNM stage and adjuvant therapy are independent risk factors for prognosis[16]. The median OS of the patients in this study was 28 months. The 1 -year survival rate was $56 \%$, the 3 -year survival rate 
was $47 \%$, and the 5 -year survival rate was $40 \%$. The survival rate in this study is higher than previous studies, probably because the data was collected retrospectively in a single center, more patients underwent radical surgery and adjuvant chemotherapy, and fewer patients in stage IV, resulting in selection bias. Univariate Cox regression analysis revealed that an elevated CA125 level, distant metastasis, and radical surgery were associated with prognosis $(\mathrm{P}<0.05)$. A multivariate analysis further revealed that distant metastasis remained an independent prognostic risk factor for survival $(P=0.038$; $\mathrm{HR}=27.016,95 \% \mathrm{Cl}: 1.205 \sim 605.664)$.

The prognosis of HAS is poor, but due to its low incidence, there is currently no standard treatment plan, and clinical treatment of HAS is similar to the treatment of CGC. Radical surgery, including the resection of liver metastases and adjuvant therapy, is considered the best treatment option. However, compared with CGC, the radical resection of HAS is more challenging because of its higher incidence of vascular invasion, lymph node metastasis and distant metastasis before surgery. Radical surgery, early pTNM and adjuvant therapy can significantly improve the prognosis of HAS [16]. One study described several different treatment options that can delay the progression of HAS, including cisplatin plus fluorouracil and epirubicin or irinotecan combined with mitomycin C[23]. Fang et al. reported a case of AFPGC patients with liver metastasis who underwent multimodal treatment including surgery, chemotherapy, interventional therapy and sorafenib targeted therapy, with an OS of 30 months[24]. Petrelli et al. reported that a case of hepatoid adenocarcinoma of pancreatic with liver, lung, and lymph node metastases treated with sorafenib had a progression-free survival time of 7 months[25]. In our study, 71.0\% (22/31) of patients underwent radical surgery, and $72.7 \%$ (16/22) of patients undergoing radical surgery received adjuvant chemotherapy. The survival rate of patients was higher than previous studies, which may be due to the fact that more patients undergo radical surgery and adjuvant chemotherapy in our group.Univariate analysis showed that radical surgery is associated with prognosis $(\mathrm{P}=0.0001 ; \mathrm{HR}=0.087,95 \% \mathrm{Cl}$ : $0.025 \sim 0.299)$, but between receiving adjuvant chemotherapy or not, the difference was not statistically significant $(\mathrm{P}=0.936 \mathrm{HR}=1.068 \varangle 95 \% \mathrm{Cl} \otimes 0.214 \sim 5.319)$. Multivariate analysis revealed that only distant metastasis is an independent prognostic risk factor for survival $(\mathrm{P}=0.038 ; \mathrm{HR}=27.016,95 \% \mathrm{Cl}$ : $1.205 \sim 605.664)$. Due to the sample size is small, risk stratification was not done based on the TNM staging of this group of patients and other risk factors. In addition, the single-center retrospective study may have a selection bias. The benefit of radical surgery and adjuvant chemotherapy need to be explored by further largescale clinical research. And whether targeted drugs such as sorafenib can be used to treat HAS also look forward to additional studies.

\section{Conclusions}

In conclusion, HAS is a rare special type of extrahepatic adenocarcinoma. The clinical symptoms are not specific compared with the CGC, but the prognosis of HAS is worse than CGC because of its frequent vascular involvement, and lymph node and liver metastasis. An elevated CA125 level, distant metastasis, and radical surgery were associated with the prognosis of HAS, and distant metastasis is an independent prognostic risk factor for survival. Due to the low incidence rate of HAS, the understanding of HAS is still insufficient from a clinical point of view, and missed diagnosis and misdiagnosis easily occur under these circumstances. Early and accurate diagnosis is required for a relatively long survival time. And aggressive multimodal treatment comprising radical gastrectomy and adjuvant chemotherapy is warranted. In addition, molecular targeted therapy also can be tried.

\section{Declarations}

\section{Ethics approval and consent to participate}

Not applicable.

\section{Patient consent for publication}

Not applicable

\section{Avaliability of date and materials}

The datasets used and/or analyzed during the current study areavailable from the corresponding author on reasonable request

\section{Competing interests}

The authors declare that they have no competing interests.

\section{Funding}

This work was supported by National Natural Science Foundation of China (Grant no.81872264).

\section{Authors' contributions}

YRQ and ZWC designed the study; CXL was the major contributor in writing the manuscript; CL, LD and WJW collected the patient data. All authors read and approved the final manuscript. 
We would like to express our gratitude to doctors from Department of Pathology for pathological diagnoses.

\section{References}

1. Su JS, Chen YT, Wang RC, Wu CY, Lee SW, Lee TY: Clinicopathological characteristics in the differential diagnosis of hepatoid adenocarcinoma: a literature review. World J Gastroentero/ 2013, 19(3):321-327.

2. Terracciano LM, Glatz K, Mhawech P, Vasei M, Lehmann FS, Vecchione R, Tornillo L: Hepatoid adenocarcinoma with liver metastasis mimicking hepatocellular carcinoma: an immunohistochemical and molecular study of eight cases. Am J Surg Patho/ 2003, 27(10):13021312.

3. Ishikura H, Kishimoto T, Andachi H, Kakuta Y, Yoshiki T: Gastrointestinal hepatoid adenocarcinoma: venous permeation and mimicry of hepatocellular carcinoma, a report of four cases. Histopathology 1997, 31(1):47-54

4. Nagai E, Ueyama T, Yao T, Tsuneyoshi M: Hepatoid adenocarcinoma of the stomach. A clinicopathologic and immunohistochemical analysis. Cancer 1993, 72(6):1827-1835.

5. Ishikura H, Kirimoto K, Shamoto M, Miyamoto Y, Yamagiwa H, Itoh T, Aizawa M: Hepatoid adenocarcinomas of the stomach. An analysis of seven cases. Cancer 1986, 58(1):119-126.

6. Baek SK, Han SW, Oh DY, Im SA, Kim TY, Bang YJ: Clinicopathologic characteristics and treatment outcomes of hepatoid adenocarcinoma of the stomach, a rare but unique subtype of gastric cancer. BMC Gastroenterol 2011, 11:56.

7. Zhou RU, Cai Y, Yang YI, Xiang J, Chen Z: Hepatoid adenocarcinoma of the stomach: A case report and review of the literature. Oncol Lett 2015, 9(5):2126-2128.

8. Liu X, Cheng Y, Sheng W, Lu H, Xu X, Xu Y, Long Z, Zhu H, Wang Y: Analysis of clinicopathologic features and prognostic factors in hepatoid adenocarcinoma of the stomach. Am J Surg Pathol 2010, 34(10):1465-1471.

9. Li T, Liu T, Wang M, Zhang M: Alpha-fetoprotein producing hepatoid gastric adenocarcinoma with neuroendocrine differentiation: A case report. Medicine (Baltimore) 2018, 97(37):e12359.

10. Lin CY, Yeh HC, Hsu CM, Lin WR, Chiu CT: Clinicopathologial features of gastric hepatoid adenocarcinoma. Biomed J 2015, 38(1):65-69.

11. Akiyama S, Tamura G, Endoh Y, Fukushima N, Ichihara Y, Aizawa K, Kawata S, Motoyama T: Histogenesis of hepatoid adenocarcinoma of the stomach: molecular evidence of identical origin with coexistent tubular adenocarcinoma. Int J Cancer 2003, 106(4):510-515.

12. Ishikura H, Fukasawa Y, Ogasawara K, Natori T, Tsukada Y, Aizawa M: An AFP-producing gastric carcinoma with features of hepatic differentiation. A case report. Cancer 1985, 56(4):840-848.

13. Liu X, Sheng W, Wang Y: An analysis of clinicopathological features and prognosis by comparing hepatoid adenocarcinoma of the stomach with AFP-producing gastric cancer. J Surg Oncol 2012, 106(3):299-303.

14. Wang Y, Sun L, Li Z, Gao J, Ge S, Zhang C, Yuan J, Wang X, Li J, Lu Z et al: Hepatoid adenocarcinoma of the stomach: a unique subgroup with distinct clinicopathological and molecular features. Gastric Cancer 2019, 22(6):1183-1192.

15. Qu BG, Bi WM, Qu BT, Qu T, Han XH, Wang H, Liu YX, Jia YG: PRISMA-Compliant Article: Clinical Characteristics and Factors Influencing Prognosis of Patients With Hepatoid Adenocarcinoma of the Stomach in China. Medicine (Baltimore) 2016, 95(15):e3399.

16. Zeng XY, Yin YP, Xiao H, Zhang P, He J, Liu WZ, Gao JB, Shuai XM, Wang GB, Wu XL et al: Clinicopathological Characteristics and Prognosis of Hepatoid Adenocarcinoma of the Stomach: Evaluation of a Pooled Case Series. Curr Med Sci 2018, 38(6):1054-1061.

17. Soreide JA, Greve OJ, Gudlaugsson E, Storset S: Hepatoid adenocarcinoma of the stomach-proper identification and treatment remain a challenge. Scand J Gastroenterol 2016, 51(6):646-653.

18. Ushiku T, Shinozaki A, Shibahara J, Iwasaki Y, Tateishi Y, Funata N, Fukayama M: SALL4 represents fetal gut differentiation of gastric cancer, and is diagnostically useful in distinguishing hepatoid gastric carcinoma from hepatocellular carcinoma. Am J Surg Pathol 2010, 34(4):533540 .

19. Kumashiro Y, Yao T, Aishima S, Hirahashi M, Nishiyama K, Yamada T, Takayanagi R, Tsuneyoshi M: Hepatoid adenocarcinoma of the stomach: histogenesis and progression in association with intestinal phenotype. Hum Pathol 2007, 38(6):857-863.

20. Osada M, Aishima S, Hirahashi M, Takizawa N, Takahashi S, Nakamura K, Tanaka M, Maehara Y, Takayanagi R, Oda Y: Combination of hepatocellular markers is useful for prognostication in gastric hepatoid adenocarcinoma. Hum Pathol 2014, 45(6):1243-1250.

21. Yang J, Wang R, Zhang W, Zhuang W, Wang M, Tang C: Clinicopathological and prognostic characteristics of hepatoid adenocarcinoma of the stomach. Gastroenterol Res Pract 2014, 2014:140587.

22. Koide N, Nishio A, Igarashi J, Kajikawa S, Adachi W, Amano J: Alpha-fetoprotein-producing gastric cancer: histochemical analysis of cell proliferation, apoptosis, and angiogenesis. Am J Gastroentero/ 1999, 94(6):1658-1663. 
23. Xie Y, Zhao Z, Li P, Wang Y, Guo C, Wang X, Tang W, Liu Q, Lu N, Xue L et al: Hepatoid adenocarcinoma of the stomach is a special and easily misdiagnosed or missed diagnosed subtype of gastric cancer with poor prognosis but curative for patients of pN0/1: the experience of a single center. Int J Clin Exp Med 2015, 8(5):6762-6772.

24. Fang YU, Wang L, Yang N, Gong X, Zhang YU, Qin S: Successful multimodal therapy for an alpha-fetoprotein-producing gastric cancer patient with simultaneous liver metastases. Oncol Lett 2015, 10(5):3021-3025.

25. Petrelli F, Ghilardi M, Colombo S, Stringhi E, Barbara C, Cabiddu M, Elia S, Corti D, Barni S: A rare case of metastatic pancreatic hepatoid carcinoma treated with sorafenib. J Gastrointest Cancer 2012, 43(1):97-102.

\section{Tables}


Table 1

The clinical characteristics and pathological findings of patients with HAS

\begin{tabular}{|c|c|c|c|c|c|c|c|c|c|c|}
\hline No. & Age/Sex & $\begin{array}{l}\text { Location } \\
\text { of tumor }\end{array}$ & $\begin{array}{l}\text { Borrmann } \\
\text { type }\end{array}$ & $\begin{array}{l}\text { Tumor } \\
\text { size(cm) }\end{array}$ & $\begin{array}{l}\text { Vascular } \\
\text { invasion }\end{array}$ & $\begin{array}{l}\text { Nerve } \\
\text { invasion }\end{array}$ & $\begin{array}{l}\text { Histologic- } \\
\text { type }\end{array}$ & $\begin{array}{l}\text { Lymph node } \\
\text { positive/total }\end{array}$ & $\begin{array}{l}\text { Distant } \\
\text { metastasis }\end{array}$ & Stage \\
\hline 1 & Male/73 & $\begin{array}{l}\text { Lower } \\
\text { third }\end{array}$ & III & $\begin{array}{l}5.5 \times \\
5.5 \times \\
11.5\end{array}$ & + & + & $M-P$ & $1 / 22$ & No & IIIA \\
\hline 2 & Male/59 & $\begin{array}{l}\text { Upper } \\
\text { third }\end{array}$ & I & $\begin{array}{l}6.5 \times \\
4.5 \times 4.0\end{array}$ & + & + & M-P & $10 / 16$ & Yes (liver) & IV \\
\hline 3 & Male/55 & $\begin{array}{l}\text { Upper } \\
\text { third }\end{array}$ & III & $\begin{array}{l}5.7 \times \\
4.5 \times 1.5\end{array}$ & - & + & M & $5 / 17$ & No & IIIA \\
\hline 4 & Male/53 & $\begin{array}{l}\text { Lower } \\
\text { third }\end{array}$ & III & $\begin{array}{l}5.5 \times \\
4.5 \times 2.0\end{array}$ & - & - & $M$ & $11 / 17$ & No & III \\
\hline 5 & Male/62 & $\begin{array}{l}\text { Lower } \\
\text { third }\end{array}$ & NA & NA & + & + & $\mathrm{P}$ & NA & $\begin{array}{l}\text { Yes (liver } \\
\text { andretroperitoneal } \\
\text { lymph node) }\end{array}$ & IV \\
\hline 6 & Female/65 & $\begin{array}{l}\text { Upper } \\
\text { third }\end{array}$ & III & $\begin{array}{l}8.0 \times \\
7.0 \times 1.5\end{array}$ & + & + & $\mathrm{P}$ & $4 / 23$ & No & III \\
\hline 7 & Male/63 & $\begin{array}{l}\text { Middle } \\
\text { third }\end{array}$ & III & $3.0 \times 4.0$ & NA & NA & M-P & NA & Yes (liver) & IV \\
\hline 8 & Female/51 & $\begin{array}{l}\text { Whole } \\
\text { stomach }\end{array}$ & IV & $15 \times 14$ & + & + & $\mathrm{P}$ & $12 / 12$ & $\begin{array}{l}\text { Yes(retroperitoneal } \\
\text { lymph node and } \\
\text { left } \\
\text { supraclavicular } \\
\text { lymph node) }\end{array}$ & IV \\
\hline 9 & Female/63 & $\begin{array}{l}\text { Upper } \\
\text { third }\end{array}$ & III & $\begin{array}{l}5 \times 4 \times \\
1.5\end{array}$ & + & + & $\mathrm{P}$ & $0 / 19$ & No & IB \\
\hline 10 & Male/64 & $\begin{array}{l}\text { Upper } \\
\text { third }\end{array}$ & III & $\begin{array}{l}4.8 \times 4 \times \\
1.5\end{array}$ & + & + & $\mathrm{P}$ & $3 / 23$ & No & IIIA \\
\hline 11 & Male/61 & $\begin{array}{l}\text { Upper } \\
\text { third }\end{array}$ & I & $\begin{array}{l}5 \times 5 \times \\
1.8\end{array}$ & - & - & $\mathrm{P}$ & $12 / 18$ & No & IIIA \\
\hline 12 & Male/64 & $\begin{array}{l}\text { Upper } \\
\text { third }\end{array}$ & III & $\begin{array}{l}3 \times 3 \times \\
0.3\end{array}$ & + & + & $P$ & $14 / 26$ & No & IIIB \\
\hline 13 & Male/54 & $\begin{array}{l}\text { Upper } \\
\text { third }\end{array}$ & III & $\begin{array}{l}4 \times 3.8 \times \\
1\end{array}$ & + & - & $P$ & $0 / 24$ & No & IIB \\
\hline 14 & Female/64 & $\begin{array}{l}\text { Upper } \\
\text { third }\end{array}$ & I & $8 \times 6 \times 2$ & + & + & M-P & $5 / 27$ & No & IIIA \\
\hline 15 & Male/53 & $\begin{array}{l}\text { Lower } \\
\text { third }\end{array}$ & NA & NA & NA & NA & $P$ & NA & $\begin{array}{l}\text { Yes (liver } \\
\text { andretroperitoneal } \\
\text { lymph node) }\end{array}$ & IV \\
\hline 16 & Male/65 & $\begin{array}{l}\text { Lower } \\
\text { third }\end{array}$ & ॥ & $\begin{array}{l}6 \times 5 \times \\
4.5\end{array}$ & - & - & $P$ & $5 / 25$ & No & IIIA \\
\hline 17 & Male/68 & $\begin{array}{l}\text { Lower } \\
\text { third }\end{array}$ & NA & NA & NA & NA & $P$ & NA & Yes (liver) & IV \\
\hline 18 & Female/69 & $\begin{array}{l}\text { Lower } \\
\text { third }\end{array}$ & III & $\begin{array}{l}1.5 \times 1 \times \\
0.5\end{array}$ & - & - & $P$ & $3 / 23$ & No & II \\
\hline 19 & Male/53 & $\begin{array}{l}\text { Lower } \\
\text { third }\end{array}$ & III & $2 \times 2 \times 1$ & + & + & $P$ & $0 / 25$ & Yes (liver) & IV \\
\hline 20 & Male/73 & $\begin{array}{l}\text { Upper } \\
\text { third }\end{array}$ & III & $\begin{array}{l}10 \times 6 \times \\
2\end{array}$ & NA & NA & M-P & $0 / 28$ & No & IIB \\
\hline 21 & Male/63 & $\begin{array}{l}\text { Upper } \\
\text { third }\end{array}$ & I & 4.5 & + & NA & M-P & $8 / 15$ & No & IIIB \\
\hline 22 & Male/60 & $\begin{array}{l}\text { Upper } \\
\text { third }\end{array}$ & II & $7 \times 4 \times 3$ & + & NA & $P$ & $8 / 50$ & No & IIIC \\
\hline
\end{tabular}




\begin{tabular}{|c|c|c|c|c|c|c|c|c|c|c|}
\hline No. & Age/Sex & $\begin{array}{l}\text { Location } \\
\text { of tumor }\end{array}$ & $\begin{array}{l}\text { Borrmann } \\
\text { type }\end{array}$ & $\begin{array}{l}\text { Tumor } \\
\text { size(cm) }\end{array}$ & $\begin{array}{l}\text { Vascular } \\
\text { invasion }\end{array}$ & $\begin{array}{l}\text { Nerve } \\
\text { invasion }\end{array}$ & $\begin{array}{l}\text { Histologic- } \\
\text { type }\end{array}$ & $\begin{array}{l}\text { Lymph node } \\
\text { positive/total }\end{array}$ & $\begin{array}{l}\text { Distant } \\
\text { metastasis }\end{array}$ & Stage \\
\hline 23 & Male/63 & $\begin{array}{l}\text { Upper } \\
\text { third }\end{array}$ & III & $\begin{array}{l}6 \times 5.5 \times \\
1.5\end{array}$ & - & NA & M-P & $0 / 20$ & No & IIB \\
\hline 24 & Female/62 & $\begin{array}{l}\text { Upper } \\
\text { third }\end{array}$ & III & $\begin{array}{l}8 \times 5.5 \times \\
1.5\end{array}$ & NA & NA & $\mathrm{P}$ & $9 / 13$ & No & IIIB \\
\hline 25 & Female/62 & $\begin{array}{l}\text { Upper } \\
\text { third }\end{array}$ & 1 & $\begin{array}{l}6 \times 3.5 \times \\
3.3\end{array}$ & NA & NA & M-P & $4 / 23$ & No & III \\
\hline 26 & Male/62 & $\begin{array}{l}\text { Upper } \\
\text { third }\end{array}$ & III & $\begin{array}{l}4 \times 3.5 \times \\
1.2\end{array}$ & - & NA & M-P & $11 / 20$ & No & IIIA \\
\hline 27 & Male/58 & $\begin{array}{l}\text { Upper } \\
\text { third }\end{array}$ & NA & NA & NA & NA & $\mathrm{P}$ & NA & No & $\| A$ \\
\hline 28 & Male/68 & $\begin{array}{l}\text { Lower } \\
\text { third }\end{array}$ & III & $\begin{array}{l}10 \times 8 \times \\
1.7\end{array}$ & + & NA & $\mathrm{P}$ & $4 / 14$ & No & IIB \\
\hline 29 & Male/48 & $\begin{array}{l}\text { Upper } \\
\text { third }\end{array}$ & NA & NA & NA & NA & $\mathrm{P}$ & NA & Yes (liver) & IV \\
\hline 30 & Female/50 & $\begin{array}{l}\text { Upper } \\
\text { third }\end{array}$ & NA & NA & NA & NA & $\mathrm{P}$ & NA & $\begin{array}{l}\text { Yes (liver } \\
\text { andretroperitoneal } \\
\text { lymph node) }\end{array}$ & IV \\
\hline 31 & Male/64 & $\begin{array}{l}\text { Upper } \\
\text { third }\end{array}$ & III & $4 \times 3$ & NA & NA & $\mathrm{P}$ & $1 / 14$ & No & IV \\
\hline
\end{tabular}


Table 2

Immunohistochemical findings of patients with HAS

\begin{tabular}{|c|c|c|c|c|}
\hline No. & Ki-67 labeling index & Glypican-3 staining & CEA staining & AFP staining \\
\hline 1 & $80 \%$ & - & NA & - \\
\hline 2 & $80 \%$ & + & NA & - \\
\hline 3 & $60 \%$ & + & NA & + \\
\hline 4 & $40 \%$ & + & - & ++ \\
\hline 5 & $50 \%$ & NA & + & ++ \\
\hline 6 & $60 \%$ & NA & NA & + \\
\hline 7 & $60 \%$ & ++ & + & ++ \\
\hline 8 & $70 \%$ & - & NA & - \\
\hline 9 & $60 \%$ & ++ & - & ++ \\
\hline 10 & $80 \%$ & + & NA & + \\
\hline 11 & $50 \%$ & NA & NA & - \\
\hline 12 & $70 \%$ & + & NA & + \\
\hline 13 & $80 \%$ & NA & NA & ++ \\
\hline 14 & $40 \%$ & + & + & ++ \\
\hline 15 & $90 \%$ & NA & NA & + \\
\hline 16 & $60 \%$ & - & + & - \\
\hline 17 & $70 \%$ & ++ & - & ++ \\
\hline 18 & $40 \%$ & NA & ++ & + \\
\hline 19 & $80 \%$ & NA & - & ++ \\
\hline 20 & $40 \%$ & NA & + & + \\
\hline 21 & $50 \%$ & NA & + & + \\
\hline 22 & $80 \%$ & - & ++ & - \\
\hline 23 & $60 \%+$ & NA & NA & - \\
\hline 24 & $90 \%+$ & NA & ++ & ++ \\
\hline 25 & $40 \%+$ & + & - & + \\
\hline 26 & $40 \%+$ & ++ & NA & ++ \\
\hline 27 & $70 \%+$ & ++ & NA & ++ \\
\hline 28 & $70 \%+$ & NA & - & ++ \\
\hline 29 & $80 \%+$ & ++ & + & ++ \\
\hline 30 & $70 \%+$ & NA & NA & ++ \\
\hline 31 & $60 \%+$ & ++ & + & + \\
\hline
\end{tabular}


Table 3

Univariate and multivariate analysis results of prognosis in patients with HAS

\begin{tabular}{|c|c|c|c|}
\hline \multirow[t]{2}{*}{ Variables } & \multicolumn{2}{|c|}{ Univariate analysis } & \multirow{2}{*}{$\begin{array}{l}\text { Multivariate analysis } \\
\text { HR }(95 \% \mathrm{Cl})\end{array}$} \\
\hline & $P$ values & $\mathrm{HR}(95 \% \mathrm{Cl})$ & \\
\hline Sex & 0.881 & $0.923(0.324 \rrbracket 2.632)-$ & - \\
\hline Age & 0.058 & $0.921(0.846 \varangle 1.003) 0.839$ & $1.010(0.917 \rrbracket 1.113)$ \\
\hline Serum CA724 level & 0.646 & $1.291(0.434 \llbracket 3.843)-$ & - \\
\hline Serum CEA level & 0.622 & $0.763(0.261 \rrbracket 2.230)-$ & - \\
\hline Serum AFP level & 0.518 & $1.958(0.256 \otimes 14.996)-$ & - \\
\hline Serum CA199 level & 0.496 & $1.546(0.441 \otimes 5.413)-$ & - \\
\hline Serum CA125 level & 0.004 & $4.587(1.612 \otimes 13.047) 0.335$ & $1.966(0.498 \rrbracket 7.771)$ \\
\hline Depth of tumor invasion(T staging) & 0.604 & $1.173(0.642 \rrbracket 2.145)-$ & - \\
\hline Lymph node staging(N staging) & 0.371 & $0.829(0.550 \otimes 1.250)-$ & - \\
\hline Distant metastasis(M staging) & 0.0001 & $16.926(4.350 \rrbracket 65.857) 0.038$ & $27.016(1.205 \rrbracket 605.664)$ \\
\hline Vascular invasion & 0.169 & $4.379(0.535 \rrbracket 35.837)$ - & - \\
\hline Nerve invasion & 0.140 & $4.965(0.592 \rrbracket 41.676)-$ & - \\
\hline Glypican-3 staining & 0.452 & $2.215(0.279 \rrbracket 17.562)-$ & - \\
\hline CEA staining & 0.257 & $0.483(0.138 \otimes 1.697)-$ & - \\
\hline AFP staining & 0.260 & 2.339(0.533ه10.259) - & - \\
\hline Radical surgery & 0.0001 & $0.087(0.025 \rrbracket 0.299) 0.603$ & $1.870(0.177 \rrbracket 19.741)$ \\
\hline Neoadjuvant chemotherapy & 0.109 & $3.869(0.739 \llbracket 20.256)$ - & - \\
\hline Adjuvant chemotherapy & 0.936 & $1.068(0.214 \llbracket 5.319)$ - & - \\
\hline
\end{tabular}

Figures 


\section{Figure 1}

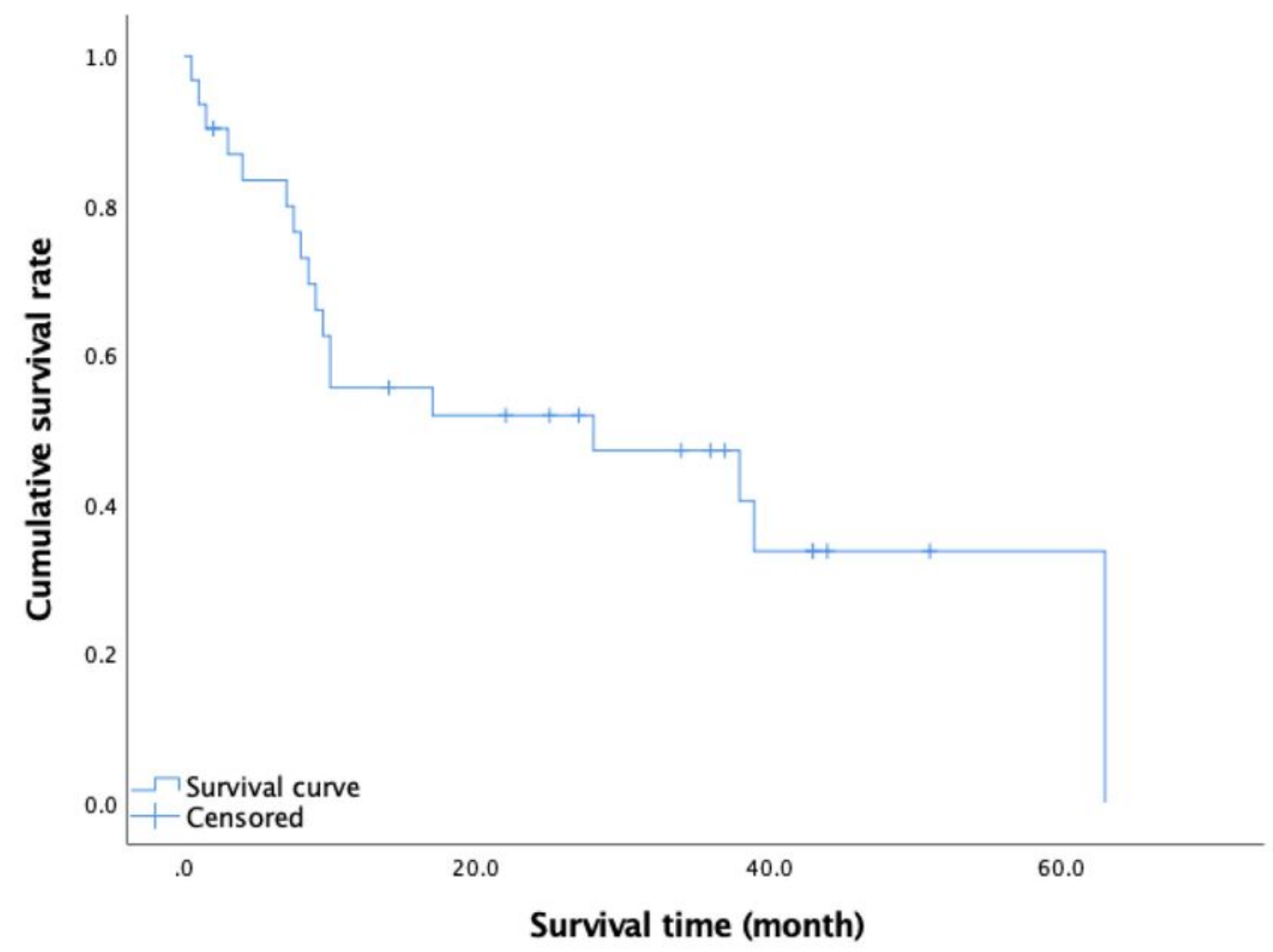

Figure 1

Kaplan-Meier survival curve of 31 patients with HAS. The median OS was 28 months. The 1 -year survival rate was $55 \%$, the 3 -year survival rate was $47 \%$, and the 5 -year survival rate was $34 \%$. 


\section{Figure 2}

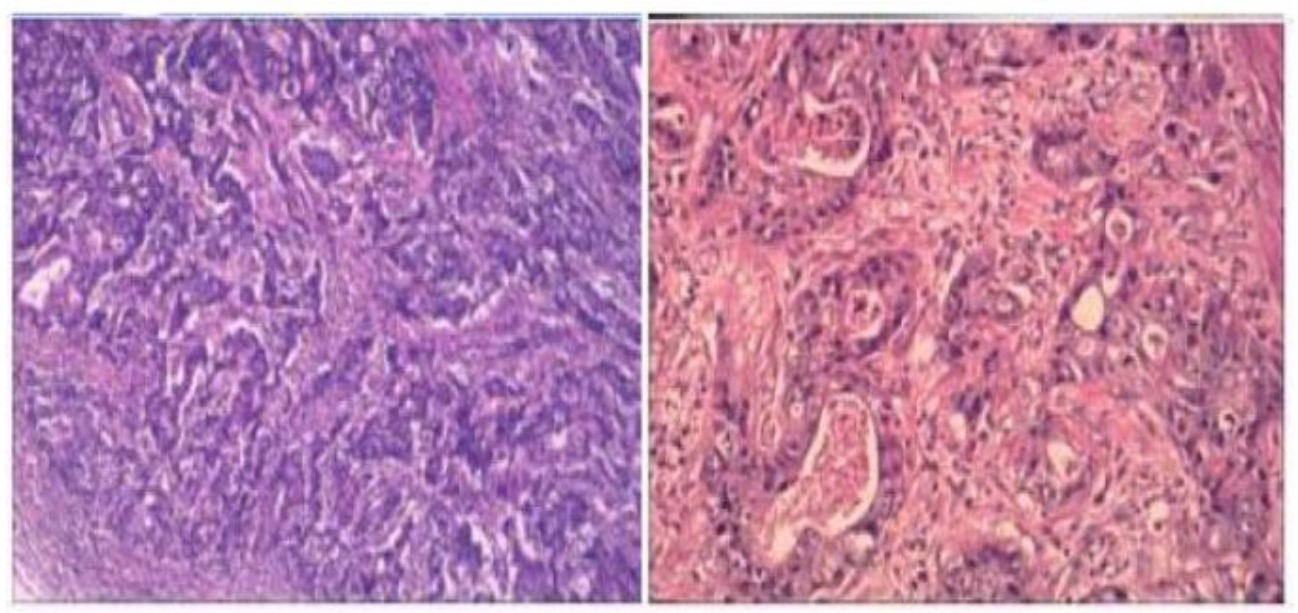

\section{Figure 2}

Histopathological findings of HAS (hematoxylin-eosin staining). Blood sinuses are quite abundant in hepatocellular differentiation area, and the tumor cells are arranged in a string (magnification 100). 